удк 005.35:005.72

\title{
ФОРМИРОВАНИЕ НОВЫХ ЭЛЕМЕНТОВ В СТРУКТУРЕ УПРАВЛЕНЧЕСКОГО СОЗНАНИЯ
}

\author{
Арутюнян Каринэ Сергеевна, \\ Karina.art.rzn@gmail.com
}

\begin{abstract}
Рязанский государственный радиотехнический университет им. В.Ф. Уткина, Россия, 390005, ул. Гагарина, 59/1.
\end{abstract}

Арутюнян Каринэ Сергеевна, кандидат философских наук, доцент кафедры истории, философии и права Рязанского государственного радиотехнического университета им. В.Ф. Уткина.

\begin{abstract}
Актуальность исследования заключается в отсутствии философского анализа структурных элементов управленческого сознания как формы общественного сознания. Не выявлены черты корпоративной, организационной, управленческой культуры и организационного поведения, которые могут способствовать преодолению социального кризиса в управлении социальными системами. Цель: проведение социально-философского анализа структурных элементов общественного сознания. Методы: анализа, синтеза, систематизации, обобщения и сравнения. Результаты отражают научную значимость работы, которая заключается в раскрытии сущности понятия культур подмены (культура как носитель кризиса в управлении и движущая сила) и культур развития (совершенствование процессов управления), которые являются базой для формирования корпоративной, организационной и управленческой культуры. Также автор вводит в научный оборот определения понятий организационной, управленческой, корпоративной культуры и организационного поведения. В ходе проведенного анализа структурных элементов управленческого сознания были выявлены факторы, способствующие формированию культур и поведения организации. Практическая составляющая проведенного исследования заключается в том, что социально-философский анализ структурных элементов управленческого сознания позволяет повысить значение управленческого сознания в решении сложных управленческих задач. В свою очередь, управленческое сознание как новая форма общественного сознания будет способствовать развитию методов, процедур, подходов, которые разрабатываются и совершенствуются в теории менеджмента. Все это связано с пониманием современного человека как носителя управленческого сознания (ценностями и ценностными ориентациями человека, которые выявляют, развивают и реализуют индивидуальность менеджера). Социально-философский анализ управленческого сознания и его элементов имеет большое значение, как теоретическое, так и практическое. Данное исследование - это вклад в методологическую базу социальной философии, теории менеджента, культурологии, социологии. Автор придерживается положения о том, что выводы исследования могут быть использованы в дальнейшем для изучения культур организации, технологий формирования культур и методик организационного поведения, а также особенностей их взаимосвязи.
\end{abstract}

Ключевые слова: Организационная культура, управленческая культура, корпоративная культура, управленческое сознание, организационное поведение, культура подмены, культура развития.

Формирование норм, принципов, идеалов в процессе управления имеет своей главной целью создать в окружающей среде определённый образ организации. Корпоративная культура как структурный элемент управленческого сознания включает в себя ценности, нормы, идеалы, установки, которые способствуют объединению большинства сотрудников корпорации для решения поставленных задач. Корпоративная культура зарождается в недрах философии корпорации и может быть определена как совокупность 
морально-этических норм, правил, которым следуют сотрудники фирмы. Философия корпорации получила свое развитие в работах таких исследователей, как Дж. Грейсон, М. Мескон, Т. Питерс [1]. Корпоративная философия выполняет функцию внутреннего объединяющего начала, договора, который добровольно заключается между людьми [2], и основана на морально-этических ценностях солидарности, которые порождают новый стиль управления и приносят удовлетворение руководителям, персоналу и клиентам. Умение использовать существующую культуру в целях управления организационными процессами является показателем корпоративной культуры [3]. Об этом свидетельствуют современные работы как российских, так и зарубежных ученых. Анализ современных источников отражает подходы в формировании культур и поведения в организации: философский, экономический, социокультурный и ценностный подходы. Вопросы, связанные с формированием культур в организации, включающие философский аспект, рассмотрены в работах следующих исследователей: В.Н. Белкин [4], И.Е. Лыскова [5], Е.Ю. Бикметов [6]. Социокультурный и ценностный подход в основном прослеживается в трудах зарубежных ученых: Durcan Bingol [7], Carmen L. Felippe [8], Damoder Suar [9], Fachar Shahzard [10], Esra Aktas [11]. Экономический фактор значимости роли культур и поведения в организации исследуется Г.В. Цукерманом [12], Е.С. Куликовой [13], Katarzyna Szczepanska-Waszcizyna [14], Rawan Abuzarqa [15].

Следует выделить разные точки зрения в определении понятия «корпоративная культура», которое впервые было введено А. Армстронгом. Корпоративная культура представляет собой определенную модель ценностей, которые не только объединяют сотрудников организации, формируют стратегию поведения, действия и взаимодействия людей, но и оказывают влияние на организационный и производственный процесс внутри организации [16]. Следующий подход в определении корпоративной культуры рассматривает данную культуру как совокупность материальных и духовных ценностей, которые определяют особенности организации, отражают ее уникальность и неповторимость, а также проявляются в организационном поведении сотрудников [17]. По словам А.В. Семенова, корпоративная культура также определяется как совокупность ценностей, идей, взглядов, которые принимаются всеми сотрудниками и являются ориентиром для организационного поведения [18].

Р. Мертон утверждает, что ценностные подходы к корпоративной культуре во многом основаны не столько на экономике корпорации, сколько на традициях, обычаях, внутренних идеалах, мировоззрении, опыте менеджера, которые обнаруживаются в производственной, экономической, социальной деятельности организации. [19]. Корпоративная культура - это нормы и правила поведения (как формальные, так и неформальные), убеждения, идеалы, ценности, образцы, включенные во все сферы компании и формирующие стратегию поведения, позволяющую эффективно решать проблемы приспособления и объединения всех элементов организации [20].

Следует подчеркнуть взаимосвязь корпоративной культуры и культуры общества, которая проявляется через систему представлений, символов, ритуалов, мифов, разделяемых членами сообщества организации.

Также корпоративная культура выступает эффективным инструментом, который используется специалистами для реализации оптимальной стратегии развития организации. Корпоративная культура позволяет реализовывать корпоративизм, в основе которого лежит система ценностей и убеждений, разделяемых всеми сотрудниками компании, и такая система определяет организационное поведение, характер повседневной деятельности, максимально развивает корпоративный дух, а также позволяет осуществлять управление компанией с учетом социально-этической ответственности. 
По мнению ряда исследователей, формирование корпоративной культуры происходит под воздействием ряда составляющих: во-первых, это представления, ценности, идеалы руководителей; во-вторых, адаптация и ответные реакции персонала на принятую систему ценностей, которые приводят к успешному решению стоящих перед организацией задач [21].

Под воздействием внешних (процессов глобализации) и внутренних факторов в формировании корпоративной культуры решающую роль играют социокультурные связи и отношения, формирующие ценности организации. Своевременная реакция на социокультурные потребности своих работников обеспечивает атмосферу сотрудничества, взаимоотношения, что является основой для формирования корпоративной культуры. Одним из факторов формирования эффективной корпоративной культуры является наличие «команды», которая транслирует корпоративные нормы и ценности, а также «личностные образцы» для персонала организации. И.И. Гофман исследовал данные процессы и пришел к выводу, что развитие организации должно быть основано на сформированных правилах и нормах [22]. Роль «личностных образцов» или подражания в распространении культуры еще в XIX в. изучал Г. Тард. Он утверждал, «что в обществе от личностей, производящих культурные нововведения, распространяются волны подражания, часто бессознательно, похожего на гипноз» [23, с. 41-46].

Проявления корпоративной культуры определяют корпоративные знания. Еще П. Друкер указывал на преимущество корпоративного знания [24]. Корпоративное знание - часть духовной культуры, которая определяется как набор принципов, фактов и навыков, правил, которые информационно обеспечивают процессы принятия решений, поведения и действия в организации [25, с. 14-26].

Основой формирования корпоративной, организационной и управленческой культуры является культура развития и культура подмены. Культура подмены выступает первоначально как субкультура по отношению к общей культуре в организацияхносителях корпоративной культуры. С течением времени культура подмены становится преобладающей и предполагает кризисность организации, смену стиля и методов управления, ценностных основ организации, форму управленческого сознания. Корпоративная культура развития предполагает ориентацию участников организации на решение задач саморазвития, совершенствования работы организации, накопление нравственности в результате постоянной ориентации участников организации на духовные ценности, их поведения, осуществления выбора, накопление знаний. Корпоративная культура выступает важным средством сдерживания развития системного кризиса, преодоления негативного действия или иных фоновых факторов глобального характера на организацию. Стратегия преодоления кризисных явлений внутри организации, выхода из кризиса должна предполагать изменения господствующей в обществе корпоративной культуры, стимулировать движение от культуры подмены к культуре развития. По мере становления корпоративная культура развития должна превратиться в доминирующую во всех организациях.

Следующим элементом управленческого сознания является организационная культура, которая формируется в организации одновременно с развитием корпоративной культуры. Отличие двух культур состоит в том, что корпоративная культура разрабатывает ценностные основы, которые являются стратегий организационного поведения. Организационная культура, сформированная корпоративной культурой, воспринимает идеологию, нормы, ценности, правила, философию, которая лежит в основе взаимоотношений как внутри, так и за пределами организации. Взаимодействие культур отражает уникальность и неповторимость организации, проявляется в поведении 
организации, отношениях сотрудников между собой, восприятии себя как личности и своей роли в корпорации [26].

Несмотря на множество определений организационной культуры, философская концепция организационной культуры не имеет однозначного и четкого определения. Актуальность изучения организационной культуры с позиций философского подхода во многом связано с потребностью развития теории и практик менеджмента, которому необходимы новые подходы к управлению, чтобы повысить эффективность труда, задействовав уровни человеческой потребности в самоактуализации. Однако при всей сложности структуры и многообразии проявлений организационной культуры, формируется точка зрения, согласно которой организационная культура представляет собой «социальный идеал организации», т. е. то, к чему организация стремится в будущем, а также выступает индикатором социальной ответственности субъектов и объектов управленческого сознания.

В определении организационной культуры сформировались три научных подхода. Рационально-прагматический подход рассматривает организационную культуру как средство повышения производительности в организации, как инструмент преобразований внутриорганизационной деятельности. Феноменологический подход актуализирует философские основы и проявления организационной культуры в корпорации. Системный подход рассматривает организационную культуру как систему, состоящую из ряда взаимосвязанных элементов: ценности, нормы, идеалы, имеющих определенные качества и свойства. Исследователь В.Н. Воронина так определяет организационную культуру как организационно-психологическую среду жизнедеятельности сотрудников организации. Организационная культура проявляется на уровне отдельной личности, группы организации в виде норм, ценностей, в структуре мотивации и стандартного поведения, в стиле управления, в структуре организации и организационноуправленческих процессах [27].

В данных подходах не учитывается основное свойство организационной культуры стратегического фактора, обеспечивающего ориентацию коллектива на сплочение для эффективности решения общих задач и достижения поставленных целей, а также мобилизации энергии и инициативы сотрудников в процессе совместной деятельности, формирования результативной системы коммуникаций в организации.

К структурным элементам организационной культуры относятся система ценностей, мифы, легенды, символы, ритуалы, язык, лозунги, ролевые модели [28]. На основе данных элементов менеджерам предприятий разрабатываются нормы и правила поведения в компании, которые объединяют коллектив на основе ключевых обозначенных и разделяемых ценностей. Таким образом, обеспечивается достижение организационных целей, создается единство действий и взглядов.

Социально-философская природа организационной культуры представляют собой систему личностно ориентированных и социальных параметров, влияющих на формирование философии корпоративности - осознание себя и своего места в организации. Социально-философский анализ организационной культуры выявил следующие элементы: миссия, философия, цели организации, которые соотносятся с социально значимыми аспектами жизнедеятельности организации. Они определяют стратегические перспективы организации и направленность организационной культуры на удовлетворение социальных интересов и потребностей, условия для непрерывного развития, повышение квалификации, проявление инициативы; система мотивации, направленная на удовлетворение потребностей; система символических действий. 
Фактором, формирующим организационную культуру, является культурная система, в рамках которой транслируются те или иные взгляды, представления, идеи, убеждения и т. д. Подход в определении культурной системы был предложен П.А. Сорокиным, который понимал культурную систему как взаимосвязанное единство норм, ценностей, идей, материальных предметов, культурных феноменов, которые могут иметь идеологическую поведенческую форму [29]. Организационная культура включает в себя элементы духовной жизни коллектива, доминирующие ценности и моральные нормы, принятый кодекс поведения, ритуалы, установленные стандарты. Главная задача организационной культуры заключается в постановке целей и задач организации, в создании реальной возможности принятия участия сотрудников коллектива в действиях по самоуправлению, а также демонстрации уникальности предприятия или события. Организационная культура не только мобилизует ресурсы организации, необходимые для достижения поставленных задач, но и является ресурсом, побуждающим менеджеров работать именно в нужном направлении, объединяющим для решения общих задач и позволяющим оперативно адаптироваться к изменениям внешней среды. Организационная культура выступает отражением материального образования - организации как социального организма и как комплекса социальных отношений в организации.

В отличие от корпоративной культуры, организационная культура основывается на философии деловой организации, которая как управленческий инструмент способствует освоению участниками организации единой системы ценностей, норм поведения, сплачивающих сотрудников организации вокруг единой цели, и формированию ценностной установки ответственного организационного поведения. Наличие развитой организационной культуры свидетельствует о некой организационной стабильности, определенном уровне устоявшихся правил и норм поведения, что позволяет осуществить организационную деятельность. В силу социальной природы индивид как личность подвергается влиянию организационной культуры, т. к. жизнь современного индивида проходит через огромное количество организаций. В результате управленческоорганизационной деятельности менеджером формируются философские основы организационной культуры (совокупность принципов организации, норм этики, правил и требований к организационному поведению, взаимодействию между сотрудниками), направленные на достижение поставленных целей в организации.

Третьим элементом управленческого сознания является управленческая культура, которая имеет определенные черты и формируется под воздействием как внутренних факторов (организационной и корпоративной культуры), так и внешних (глобализационные процессы и явления) [30]. Как было отмечено ранее, управленческая культура находится под влиянием организационной и корпоративной культуры. Исследователь Р. Рютингер полагал, что управленческая культура представляет собой совокупность норм, правил, принципов, которые являются регуляторами отношений между субъектом-объектом управления [31].

Управленческая культура - это система регулирования управленческих процессов в организациях правильного распределения полномочий и использования профессиональных компетенций. В управленческую культуру включаются потребности, мотивационные установки сотрудников, формирование духовно-нравственной атмосферы, позволяющей выстраивать эффективный управленческий процесс между субъектом (носителем управленческого сознания) и объектом управления.

Исследователь Н.В. Лизина предлагает рассматривать управленческую культуру в рамках гносеологического и онтологического подхода. Гносеологический подход рассматривает управленческую культуру через понятийное поле организационной и кор- 
поративной культуры. Онтологический подход предполагает определение логических оснований «социальных пространств» бытия культуры и управления, выявления их сущностных и существенных отношений, определения фактов, порождающих культуру управления [32].

Поведение в организации во многом определяется сформированными культурами организации. Под организационным поведением понимают поведение сотрудников организации в типовых ситуациях, связанных с выполнением организационноуправленческих задач в условиях управленческой ситуации.

Организационное поведение - это сложноорганизованный процесс, который имеет множество подходов. С.П. Роббинс определяет организационное поведение как научную дисциплину, предвидение и управление человеческим поведением в рамках организации [33]. По Дж. Ньюстрому, организационное поведение - это изучение поведения людей в организациях и практическое использование полученных знаний [34]. Исследователь Ю.Д. Красовский определял организационное поведение как систему норм, правил, выработанных культурой организации, принятых сотрудниками корпорации. Рационально спланированное организационное поведение является результатом эффективной управленческой деятельности, а также управленческих отношений, складывающихся между менеджером и сотрудниками [35]. Ряд ученых определяют организационное поведение сотрудников организации в типовых ситуациях, связанных с выполнением организационно-управленческих задач в условиях управленческой ситуации.

Также рассматривают организационное поведение как науку и научную дисциплину, в которой выделяются следующие предметные области: поведение организаций, проявляющиеся в отношении людей; поведение людей в этих организациях, проявляющееся в отношении другу друга и организации в целом; определение причин и факторов поведения людей в социальной организации.

Таким образом, в числе внешних факторов формирования культур организации и поведения необходимо определить роль фоновых факторов глобального характера, которые в современном мире оказывают определяющее влияние: среди них - системный цивилизационный (глобальный) кризис, который пронизывает все сферы общественной жизни. Социально-экономические и социально-политические изменения стратегического характера, затрагивающие мировоззрение, систему ценностей, образ жизни, также влияют на формирование культур организации. Современные структурные компоненты управленческого сознания в условиях глобального кризиса реагируют на происходящие стратегические изменения в глобальном мире. Для преодоления кризисных явлений, появляющихся в результате глобальных проявлений внутри организации необходимо стимулировать движение от культуры подмены к культуре развития. Необходимо, чтобы культуры в организациях основывались и на культуре развития и обретали их черты. Роль государства и менеджеров организации является определяющей и ведущей.

\section{СПИСОК ЛИТЕРАТУРЫ}

1. Лагунова Л.Б. Корпорация как тип социальной интеграции // Социс. - 1996. - № 12. - С. $105-112$.

2. Чумиков А.Н. Креативные технологии паблик рилейшенз. - М.: Универ. гуманитар. лицей, 1998. $215 \mathrm{c}$.

3. Бикметов Е.Ю. Организационное знание как фактор воспроизводства корпоративной культуры // Социальная политика и социология. - 2013. - № 5. - С. 186-193.

4. Белкин В.Н. Содержание и роль корпоративной культуры в российских организациях // Журнал экономической теории. - 2018. - № 3. - Т. 5. - С. 449-461. 
5. Лыскова И.Е. Миссия, философия и стратегия организации в системе организационной культуры // Вестник Коми республиканской академии государственной службы и управления. Серия «Теория и практика управления». - 2017. - № 2. - С. 231-236.

6. Бикметов Е.Ю. Духовно-культурные регуляторы в управлении организационного поведения // Управление экономикой: метод, модели, технологии: XIV международная научно-практическая конференция. - Уфа, Павловка: УГАТУ, 2016. - С. 373-377.

7. Durcan Bingol. The effect of organizational culture image and identity // Procedia - Social and Behavioral Sciences. - 2013. - V. 99. - P. 222-229.

8. Felippe C.L. Impact of organizational culture values on organizational agility // Sustainability. - 2017. № 9 (12). - P. 23-54.

9. Damoder Suar. Influence of organizational culture on organizational effectiveness // Sage journals - 2017. № 4. - P. 123-128.

10. Fachar Shahzard. Impact of organizational culture on organizational performance: an overview // Interdisciplinary journal of contemporary research in business. - 2012. - № 9. - V. 3. - P. 975-985.

11. Esra Aktas. The Effect of organizational culture on organizational efficiency: the moderating role of organizational environment and CEO values // Procedia: Social and Behavioral Sciences. - 2011. - V. 24. P. 1560-1573.

12. Цукерман Г.В. Корпоративная культура бизнес-трактовки и специфика социокультурного прочтения // Челябинский гуманитарий. - 2016. - № 3 (36). - С. 22-28.

13. Куликова Е.С. Корпоративная культура компании как основа внутреннего маркетинга // Наука: вчера, сегодня, завтра. - 2016. - № 9 (31). - С. 120-126.

14. Szczepanska-Woszcizyna K. Leadership and organizational culture as the normative influence of top management on employees behavior in the innovation process // Procedia economics and Finance. - 2015. V. 30. - P. 396-402.

15. Rawan Abuzarqa. The relationship between organizational culture, risk management and organizational performance // Cross-cultural management journal. - 2019. - Iss. 1. - P. 13-20.

16. Армстронг М. Практика управления человеческими ресурсами. - СПб.: Питер, 2010. - 824 с.

17. Спивак В.А. Корпоративная культура: теория и практика. - СПб.: Питер, 2001. - 345 с.

18. Семенов А.В. Инновационные аспекты управления корпоративными знаниями. - М.: Дашков и К, 2013. $-148 \mathrm{c}$

19. Здравомыслов А.Г. Социология конфликта. - М.: Аспект-Пресс, 1995. - 319 с.

20. Макарова Е.А. Социальный аспект внутреннего маркетинга организации // Социальные инновации в развитии трудовых отношений и занятости в ХХ в. - Н. Новгород: Изд-во НИСОЦ, 2014 - С. $416-419$

21. Шейн Э. Организационная культура и лидерство. - М.: Питер, 2011. - 330 с.

22. Гофман И. Представление себя другим в повседневной жизни. - М.: Канон-Пресс, 2000. - 304 с.

23. Тард Г. Законы подражания. - М.: Академический проект, 2011. - 304 с.

24. Друкер П. Задачи менеджмента в ХХІ в. - М.: Вильямс, 2001. - 272 с.

25. Стоунхаус Д. Управление организационным знанием // Менеджмент в России и за рубежом. 1999. - № 1. - C. 14-26.

26. Мильнер Б.3. Теория организации. - М.: Инфра-М, 2006. - 558 с.

27. Воронин В.Н. Социально-психологические механизмы формирования организационной культуры: дис. ... д-ра психол. наук. - М., 1999. - 328 с.

28. Камерон К. Диагностика и изменение организационной культуры. - СПб.: Питер, 2001. - 310 с.

29. Сорокин П. Человек. Цивилизация. Общество. - М.: Политиздат, 1992. - 542 с.

30. Васьков М.А. Теоретико-методологические подходы к анализу управленческой культуры // Россия реформирующаяся: ежегодник. - 2010. - Вып. 9. - С. 61-75 с.

31. Рюттингер Р. Культура предпринимательства. - М.: ЭКОМ, 1992. - 237 с.

32. Лизина Н.В. Управленческая культура как качественный показатель // Ползуновский вестник. 2006. - № 1. - С. 231-234.

33. Роббинс С.П. Менеджмент. - М.: Вильямс, 2002. - 880 с.

34. Ньюстром Дж. Организационное поведение. Поведение человека на рабочем месте. - СПб: Питер, 2000. - $497 \mathrm{c}$

35. Красовский Ю.Д. Организационное поведение. - М.: ЮНИТИ-ДАНА, 2003. - 510 с.

Поступила 21.10.2019 2. 
UDC 005.35:005.72

\title{
FORMATION OF NEW ELEMENTS IN THE STRUCTURE OF THE MANAGEMENT CONSCIOUSNESS
}

\author{
Karine S. Arutiunian, \\ Karina.art.rzn@gmai.com

\begin{abstract}
Ryazan State Radio Engineering University named after V.F. Utkin, 59/1, Gagarin street, Ryazan, 390005, Russia.
\end{abstract}

Karine S. Arutiunian, Cand. Sc., associate professor, Ryazan State Radio Engineering University named after V.F. Utkin.

The relevance of the research lies in the lack of philosophical analysis of the structural elements management consciousness as the form public consciousness. The characteristics of the corporate, organizational, management culture and organizational behaviour have not been identified. that can contribute to overcoming the social crisis in the management of social systems. The aim of the study is to carry out social and philosophical analysis of structural elements of public consciousness. Methods: of analysis, synthesis, systematization, generalization and comparison. The results of the study reflect scientific significance of the work, which consists in revealing essence of the concept substitution cultures (culture as the crisis in management and the driving force) and development cultures (improvement of management processes), which are the basis for the formation of corporate, organizational and management culture. The author introduces as well into scientific circulation the definitions of the concepts of organizational, management, corporate culture and organizational behavior. The practical component of the research is that the social and philosophical analysis of the structural elements management consciousness allows increasing the role and importance of management consciousness in solving complex management problems. The management consciousness, as a new form of social consciousness, in its turn will contribute to the development of the methods, procedures, approaches that are developed and improved in management theory. All this is related to understanding of modern man as the management consciousness, his values and value orientations, the most important of which is identification, development and realization of the individuality. The socio-philosophical analysis of the management consciousness and its elements has great theoretical and practical significance. This study is contribution to the methodological base of social philosophy, management theory, cultural studies, sociology. The author maintains the provision that the results of the research can be used in the future to study cultures of organization and behavior, technologies of formation of cultures and methods of organizational behavior, as well as peculiarities of their relationship

Key words: Organizational culture, management culture, corporate culture, management consciousness, organizational behavior, substitution culture, development culture.

\section{REFERENCES}

1. Lagunova L.B. Korporatsiya kak tip sotsialnoy integratsii [Corporation as a type of social integration]. Sotsiologicheskie issledovaniya, 1996, no. 12, pp. 105-112.

2. Chumikov A.N. Kreativnye tekhnologii pablik rileyshenz [Creative technologies of public relations]. Moscow, University humanitarian lyceum Publ., 1998. 215 p.

3. Bikmetov E.Yu. Organizatsionnoe znanie kak faktor vosproizvodstva korporativnoy kultury [Organizational knowledge as a factor of reproduction of corporate culture]. Sotsialnaya politika $i$ sotsiologiya, 2013, no. 5, pp. 186-193.

4. Belkin V.N. Soderzhanie i rol korporativnoy kultury v rossiiskikh organizatsiyakh [Content and role of corporate culture in Russian organizations]. Zhurnal ekonomicheskoy teorii, 2018, no. 3, vol. 5, pp. 449-461. 
5. Lyskova I.E. Missiya, filosofiya i strategiya organizatsii v sisteme organizatsionnoy kultury [Mission, philosophy and strategy of organization in the system of organizational culture]. Vestnik Komi respublikanskoy akademii gosudarstvennoy sluzhby i upravleniya. Seriya «Teoriya i praktika upravleniya», 2017, no. 2, pp. 231-236.

6. Bikmetov E.Yu. Dukhovno-kulturnye regulyatory v upravlenii organizatsionnogo povedeniya [Spiritual and cultural regulators in management of organizational behavior]. XIV mezhdunarodnaya nauchnoprakticheskaya konferentsiya. Upravlenie ekonomikoy: metod, modeli, tekhnologii [Management of economy: method, models, technologies. Materials XIV international scientific and practical conference]. Ufa, Pavlovka, USATU Publ., 2016. pp. 373-377.

7. Durcan Bingol. The effect of organizational Culture image and identity. Procedia - Social and Behavioral Sciences, 2013, vol. 99, pp. 222-229.

8. Felippe C.L. Impact of organizational culture values on organizational agility. Sustainability, 2017, no. 9 (12), pp. 23-54.

9. Damoder Suar. Influence of organizational culture on organizational effectiveness. Sage journals, 2017, no. 4, pp. 123-128.

10. Fachar Shahzard. Impact of organizational culture on organizational performance: an overview. Interdisciplinary journal of contemporary research in business, 2012, no. 9, vol. 3, pp. 975-985.

11. Esra Aktas. The effect of organizational culture on organizational efficiency: the moderating role of organizational environment and CEO values. Procedia: Social and Behavioral Sciences, 2011, vol. 24, pp. 1560-1573.

12. Zukerman G.V. Korporativnaya kultura biznes-traktovki i spetsifika sotsiokulturnogo prochteniya [Corporate culture of business interpretation and specifics of sociocultural reading]. Chelyabinskiy gumanitariy, 2016, no. 3 (36), pp. 22-28.

13. Kulikova E.S. Korporativnaya kultura kompanii kak osnova vnutrennego marketinga [Corporate culture of the company as the basis of internal marketing]. Nauka: vchera, segodnya, zavtra, 2016, no. 9 (31), pp. $120-126$.

14. Szczepanska-Woszcizyna K. Leadership and organizational culture as the normative influence of top management on employees behavior in the innovation process. Procedia economics and finance, 2015, vol. 30, pp. 396-402.

15. Rawan Abuzarqa. The relationship between organizational culture, risk management and organizational performance. Cross-cultural management journal, 2019, Iss. 1, pp. 13-20.

16. Armstrong M. Praktika upravleniya chelovecheskimi resursami [Practice of Human Resource Management]. St. Petersburg, Piter Publ., 2010. 824 p.

17. Spivak V.A. Korporativnaya kultura: teoriya i praktika [Corporate culture: theory and practice]. St. Petersburg, Piter Publ., 2001. 345 p.

18. Semenov A.V. Innovatsionnye aspekty upravleniya korporativnymi znaniyami [Innovative aspects of corporate knowledge management]. Moscow, Dashkov and K Publ., 2013. 148 p.

19. Zdravomyslov A.G. Sotsiologiya konflikta [Sociology of Conflict]. Moscow, Aspect-Press Publ., 1995. 319 p.

20. Makarova E.A. Sotsialny aspect vnutrennego marketinga organizatsii [The social aspect of internal marketing organization]. Sotsialnye innovatsii $v$ razvitii trudovykh otnosheniy $i$ zanyatosti $v X X v$. [Social innovations in development of the labor relations and employment in XX century]. N. Novgorod, NISOTS Publ., 2014. pp. 416-418.

21. Shane E. Organizatsionnaya kultura i liderstvo [Organizational culture and leadership]. Moscow, Piter Publ., 2011. 330 p.

22. Gofman I. Predstavlenie sebya drugim v povsednevnoy zhizni [Presenting himself to others in everyday life]. Moscow, Kanon-Press Publ., 2000. 304 p.

23. Tard G. Zakony podrazhaniya [Laws of imitation]. Moscow, Akademicheskiy proekt Publ., 2011. 304 p.

24. Drucker P. Zadachi menedzhmenta v XXI v. [Management challenges in the $21^{\text {st }}$ century]. Moscow, Vilyams Publ., 2001. 272 p.

25. Stonehouse D. Upravlenie organizatsionnym znaniem [Management of organizational knowledge]. Menedzhment v Rossii i za rubezhom, 1999, no. 1, pp. 14-26.

26. Milner B.Z. Teoriya organizatsii [Theory of organization]. Moscow, Infra-M Publ., 2006. 558 p.

27. Voronin V.N. Sotsialno-psikhologicheskie mekhanizmy formirovaniya organizatsionnoy kultury. Dis. Dokt. nauk [Socio-psychological mechanisms of formation of organizational culture. Dr. Diss.]. Moscow, 1999. $328 \mathrm{p}$.

28. Cameron K. Diagnostika i izmenenie organizatsionnoy kultury [Diagnostics and changing of organizational culture]. St. Petersburg, Piter Publ., 2001. 310 p. 
29. Sorokin P. Chelovek. Tsivilizatsiya. Obshchestvo [Man. Civilization. Society]. Moscow, Politizdat Publ., 1992. $542 \mathrm{p}$.

30. Vaskov M.A. Teoretiko-metodologicheskie podkhody k analizu upravlencheskoy kultury [Theoretical and methodological approaches to analysis of management culture]. Rossiya reformiruyushchayasya. Ezhegodnik, 2010, Iss. 9, pp. 61-75.

31. Ryuttinger R. Kultura predprinimatelstva [Culture of entrepreneurship]. Moscow, EKOM Publ., 1992. $237 \mathrm{p}$.

32. Lizina N.V. Upravlencheskaya kultura kak kachestvenny pokazatel [Management culture as a qualitative indicator]. Polzunovskiy vestnik, 2006, no. 1, pp. 231-234.

33. Robbins S.P. Menedzhment [Management]. Moscow, Vilyams Publ., 2002. 880 p.

34. Newstrom J. Organizatsionnoe povedenie. Povedenie cheloveka na rabochem meste [Organizational behavior. Human behavior in the workplace]. St. Petersburg, Piter Publ., 2000. 497 p.

35. Krasnovsky Yu.D. Organizatsionnoe povedenie [Organizational behavior]. Moscow, UNITY-DANA Publ., 2003. 510 p.

Received: 21 October 2019. 